\title{
TEMPERATURE AND DWELL DEPENDENCE OF FATIGUE CRACK PROPAGATION IN VARIOUS HEAT TREATED TURBINE DISC ALLOYS.
}

\author{
S. Everitt ${ }^{1}$, M.J. Starink ${ }^{1}$ and P.A.S. Reed ${ }^{1}$ \\ ${ }^{1}$ Materials Research Group, School of Engineering Sciences, University of Southampton, Southampton, SO17 1BJ, UK
}

Keywords: Fatigue Crack Propagation, Apparent Activation Energy, N18, U720Li, U720Li(LG), RR1000

\begin{abstract}
Four turbine disc alloys: N18, U720Li (in two grain sizes) and RR1000 are compared in terms of crack propagation behaviour at $650^{\circ} \mathrm{C}$ and $725^{\circ} \mathrm{C}$ in air and vacuum under $1-1-1-1$ and $1-20-1-1$ trapezoidal loading. Fractographic analysis, together with crack propagation analysis under the varying test conditions has been combined with a novel apparent activation energy analysis approach, to assess the multi-mechanistic processes operating. Oxidation fatigue seems to be the dominant time-dependent process while the best oxidation resistance appears to be shown by RR1000. A larger grain size confers a benefit for crack growth behaviour in time-dependent fatigue (in the absence of other factors). The grain boundary character of RR1000 and N18 is deduced to play an important role in their improved high temperature fatigue crack growth resistance over the U720Li variants.
\end{abstract}

\section{Introduction}

Fatigue failure of gas turbine discs at higher temperatures, above $500^{\circ} \mathrm{C}$, occurs predominantly by time-dependent, intergranular crack propagation. The rate at which this progresses is controlled by microstructural features of the material such as grain size, grain boundary character and the amount, size and coherency of the gamma prime $\left(\gamma^{\prime}\right)$ precipitates in the material. These features are controlled by both alloy chemistry and subsequent heat treatments.

In this work results of high temperature fatigue tests carried out on four Ni based superalloy materials in air and vacuum at $650^{\circ} \mathrm{C}$ and $725^{\circ} \mathrm{C}$ and under two dwell conditions will be presented, this work extends and builds upon comparisons published elsewhere [1]. The alloys studied are N18, RR1000 [2], Udimet 720Li (U720Li) and U720Li Large Grain (U720Li-LG) variant [3] (U720Li-LG is an experimental variant produced by solution heat treating U720Li at a somewhat higher temperature). The influence of composition, sub-solvus heat treatments and cooling rates, along with the resultant grain size, $\gamma^{\prime}$ size and distribution on fatigue crack propagation behaviour are compared and contrasted using conventional assessments of crack growth rate and fractography differences under the range of test conditions. In addition, changes in failure mechanism will be analysed using a novel method [4] which considers the apparent activation energy of the failure process.

\section{Materials}

The compositions of the three alloys studied are presented in Table I and the heat treatments applied are presented in Table II. The RR1000 alloy studied is an early generation version of this alloy.

Table I Composition of alloys (wt. \%)

\begin{tabular}{|l|c|c|c|c|c|c|c|c|c|c|c|c|}
\hline Alloy & $\mathrm{Co}$ & $\mathrm{Cr}$ & $\mathrm{Mo}$ & $\mathrm{Al}$ & $\mathrm{Ti}$ & $\mathrm{Hf}$ & $\mathrm{C}$ & $\mathrm{B}$ & $\mathrm{W}$ & $\mathrm{Fe}$ & $\mathrm{Zr}$ & $\mathrm{Ta}$ \\
\hline N18 & 15.4 & 11.1 & 6.44 & 4.28 & 4.28 & 0.50 & 0.022 & 0.008 & --- & --- & 0.019 & --- \\
\hline \multirow{2}{*}{ RR1000 } & $14.0-19.0$ & $14.35-$ & $4.25-5.25$ & $2.85-3.15$ & $3.45-4.15$ & $0.5-1.0$ & $0.012-$ & $0.01-$ & -- & $0.0-1.0$ & $0.05-0.07$ & $1.35-2.15$ \\
\hline U720Li \& LG & 14.57 & 15.92 & 2.98 & 2.44 & 5.18 & --- & 0.023 & 0.016 & 1.35 & 0.08 & 0.042 & --- \\
\hline
\end{tabular}

Table II Material yield strength, $\gamma^{\prime}$ solvus (as quoted in the literature) and heat treatment comparison at $650^{\circ} \mathrm{C}$. Where two references are given a rounded average of reported values are included in the table. (* all ageing heat treatments were followed by an air cool)

\begin{tabular}{|l|c|c|cc|cc|}
\hline Alloy & $\sigma_{\mathrm{y}}$ at $650^{\circ} \mathrm{C}$ & $\gamma^{\prime}$ solvus & \multicolumn{2}{|c|}{ Solution heat treatment } & \multicolumn{2}{|c|}{ Ageing heat treatments* } \\
\hline N18 & $1031 \mathrm{MPa}[5]$ & $1190^{\circ} \mathrm{C}[6]$ & $4 \mathrm{~h} 1165^{\circ} \mathrm{C}$ & air cool & $24 \mathrm{~h} 700^{\circ} \mathrm{C}$ & $4 \mathrm{~h} 800^{\circ} \mathrm{C}$ \\
\hline RR1000 & $970 \mathrm{MPa}[7]$ & $1160^{\circ} \mathrm{C}[2,7]$ & $4 \mathrm{~h} 1120^{\circ} \mathrm{C}$ & fan air cool & $24 \mathrm{~h} 650^{\circ} \mathrm{C}$ & $16 \mathrm{~h} 760^{\circ} \mathrm{C}$ \\
\hline U720Li & $980 \mathrm{MPa}[3]$ & $1160^{\circ} \mathrm{C}[2,8]$ & $4 \mathrm{~h} 1105^{\circ} \mathrm{C}$ & oil quench & $24 \mathrm{~h} 650^{\circ} \mathrm{C}$ & $16 \mathrm{~h} 760^{\circ} \mathrm{C}$ \\
\hline U720Li-LG & $850 \mathrm{MPa}[3]$ & $1160^{\circ} \mathrm{C}[2,8]$ & $4 \mathrm{~h} 1135^{\circ} \mathrm{C}$ & air cool & $24 \mathrm{~h} 650^{\circ} \mathrm{C}$ & $16 \mathrm{~h} 760^{\circ} \mathrm{C}$ \\
\hline
\end{tabular}

\section{Experimental Methods}

The microstructures of the materials have been studied using optical microscopy and scanning electron microscopy (SEM). Specimens were polished to a $1 \mu \mathrm{m}$ finish and then electrolytically etched using an orthophosphoric acid solution typically for 3 to 4 seconds. Micrographs were obtained using both an Olympus
BH-2 optical microscope and a JSM 6500F field emission gun scanning electron microscope (FEG-SEM). Grain sizes were estimated using automatic image analysis software or the lineintercept method. Further characterisation of secondary and tertiary $\gamma^{\prime}$ was carried out by creating either carbon replicas or thin film samples and analysing these in a JEOL JEM 3010 transmission electron microscope (TEM). 
Fatigue testing was carried out in three point bend conditions on a single edge notched bend specimens (SENB) in air and vacuum at $650^{\circ} \mathrm{C}$ and $725^{\circ} \mathrm{C}$. Testing in air was carried out using an Instron 8501 servo-hydraulic testing machine fitted with an ESH Ltd. high temperature vacuum chamber. Heating was provided by four high intensity quartz lamps. Temperature was monitored and controlled to $\pm 2{ }^{\circ} \mathrm{C}$ using an R-type (platinum $+13 \%$ rhodium/platinum) thermocouple spot welded to the specimen within the hot zone and a Eurotherm 815 thermo-controller. For tests in vacuum this set up was augmented with an Edwards rotary vacuum pump, Balzers TPU240 Turbomolecular vacuum pump and TCP380 Electronic drive unit linked to Balzers Pirani and Cold cathode pressure gauge heads and TPG300 pressure gauge and controller, which allowed the ESH Ltd. test chamber to be evacuated to an indicated pressure of $1 \times 10^{-5} \mathrm{mb}$. Crack length was monitored using either direct current (DC) or pulsed DC electrical potential difference (p.d.) method and corrected posttest using a linear correction factor obtained from optical measurements of initial and final crack length measurements.

For tests carried out in air, precracking was carried out using a triangular wave form, with $\mathrm{R}=0.1$ a frequency of $20 \mathrm{~Hz}$ and an initial $\Delta \mathrm{K}=20 \mathrm{MPa} \sqrt{\mathrm{m}}$, which was stepped down in $10 \%$ increments after the crack had grown through at least four plastic zone sizes until $\Delta \mathrm{K} \approx 15 \mathrm{MPa} \sqrt{\mathrm{m}}$ was achieved. This ensured that crack growth out would occur from a microscopically sharp crack away from any residual effects induced in the machining of the notch. The cyclic loading was changed to a $1-1-1-1$ or a $1-20-1-1$ trapezoidal waveform, $\mathrm{R}=0.1$ and the crack allowed to propagate to failure under constant load (increasing $\Delta \mathrm{K}$ ) conditions. Tests carried out under vacuum conditions were conducted in a similar manner to the air tests, with the following differences. At the end of the precracking stage the ESH Ltd. chamber was evacuated until a pressure equal to or less than $1 \times 10^{-5} \mathrm{mb}$ was attained. Heat was then applied to raise the specimen to the required test temperature $\left(650^{\circ} \mathrm{C}\right.$ or $\left.725^{\circ} \mathrm{C}\right)$, this led to outgassing of the chamber and specimen resulting in a reduction in the quality of the vacuum. Crack growth out using either a 1-1-1-1 trapezoidal waveform $(0.25 \mathrm{~Hz})$ or 1-20-1-1 trapezoidal waveform was started once the vacuum had recovered to $1 \times 10^{-5} \mathrm{mb}$.

\section{Results}

Optical micrographs of all four materials are shown in Figure 1. The grain size of U720Li-LG is the coarsest, ranging between 4.8$41.3 \mu \mathrm{m}$, with N18 the next coarsest 0.6-22.9 $\mu \mathrm{m}$, whilst RR1000 and $\mathrm{U} 720 \mathrm{Li}$ have finer grain sizes ranging between, 2.3-16.0 $\mu \mathrm{m}$ and 2.1-13.1 $\mu \mathrm{m}$, respectively. (a)

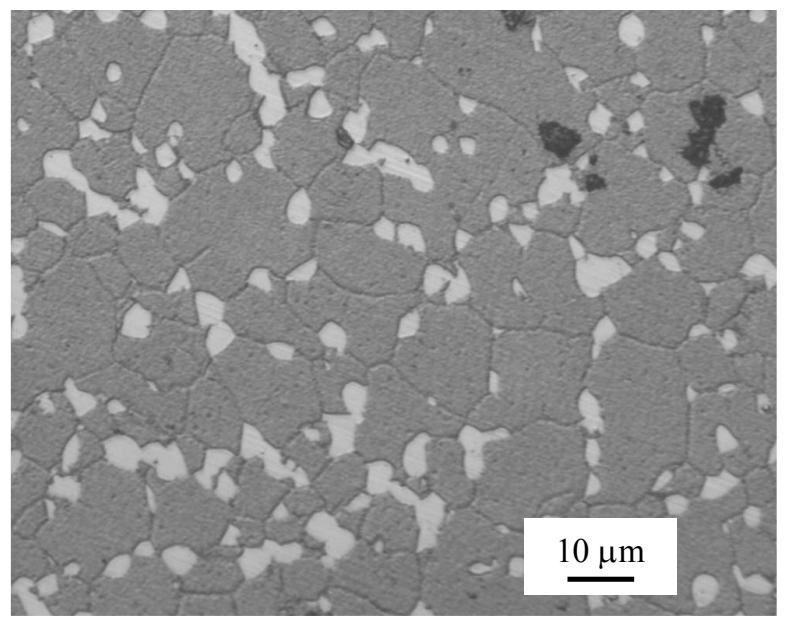

(c)

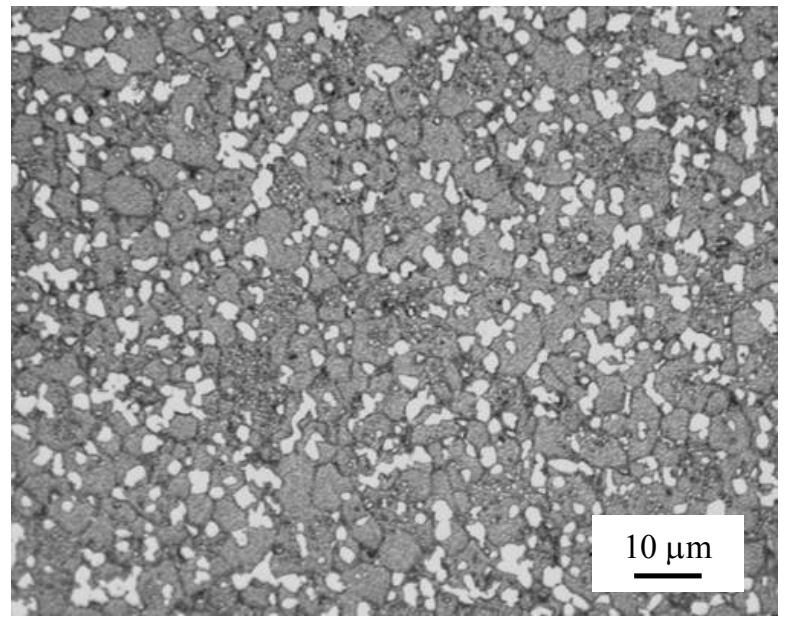

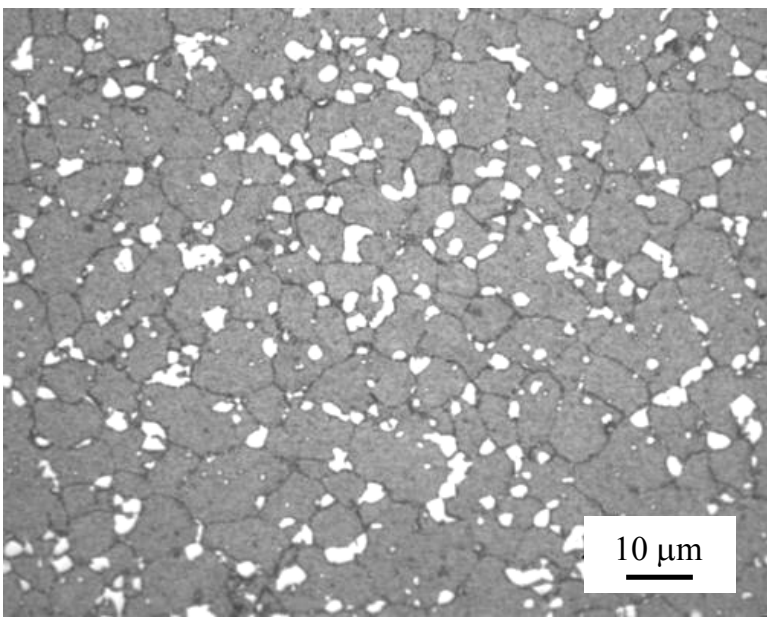

(b)

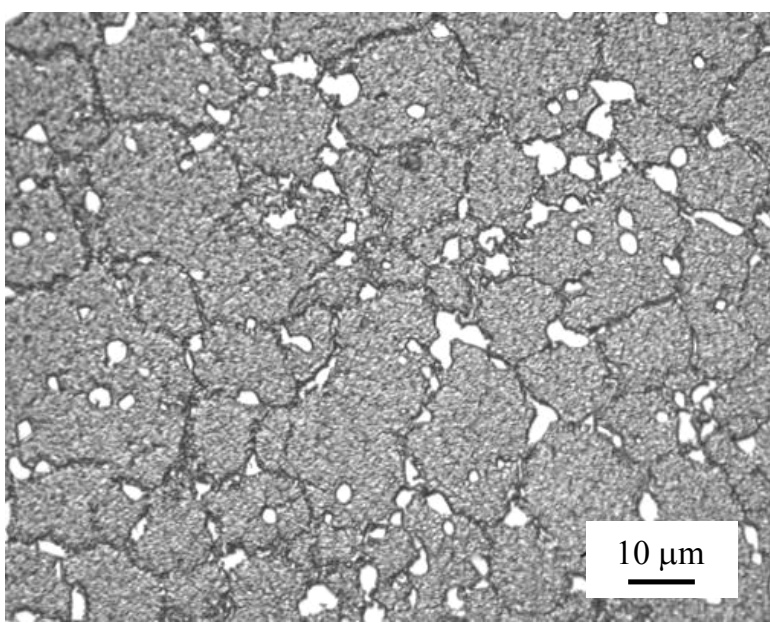

(d)

Figure 1 Optical micrographs of N18 (a), RR1000 [9] (b), U720Li [9] (c) and U720Li LG [9] (d) Orthophosphoric etch. 
(a)
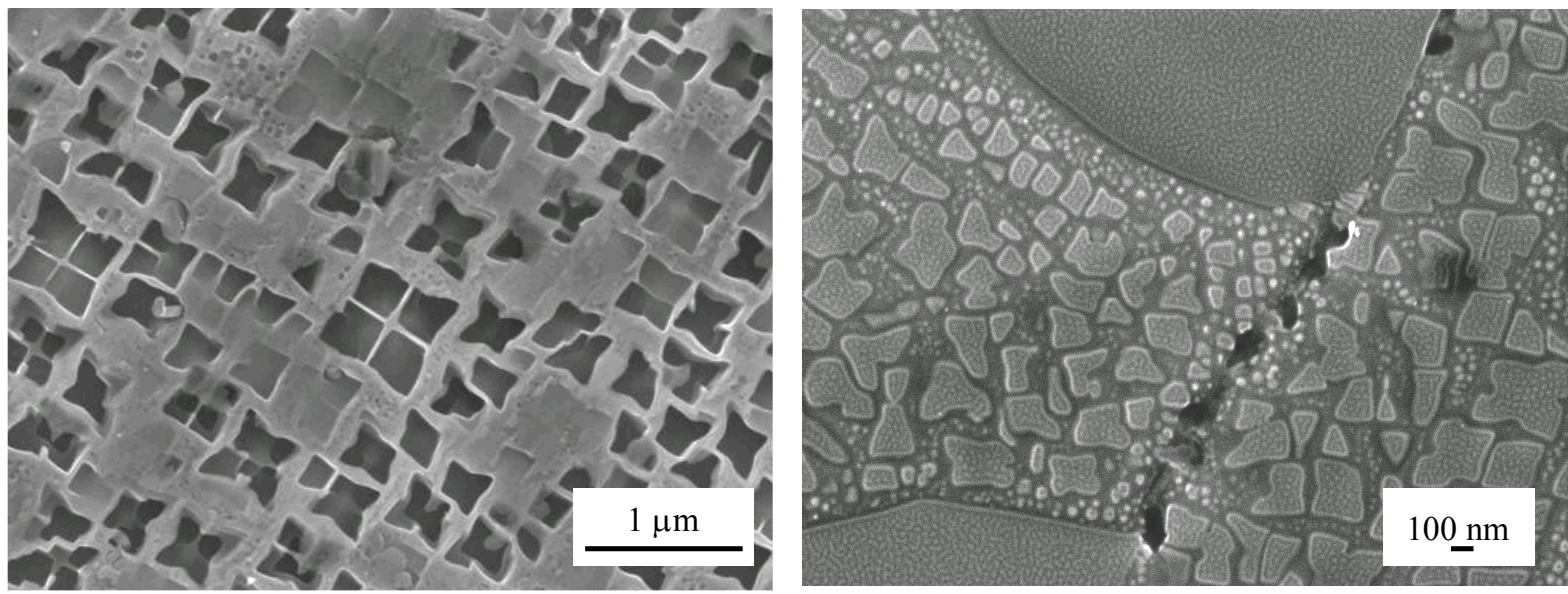

Figure 2 N18 Nimonic etch FEG SEM SEI mode (a); N18 Electro polished FEG SEM SEI mode (b)

Secondary $\gamma^{\prime}$ sizes were assessed in the FEG-SEM, examples are shown in Figure 2 for N18. Note in Figure 2(b) fine scale grain boundary particles can be deduced to exist on the grain boundary (although they cannot be analysed as they have been electropolished out. This assessment showed that N18 has a coarser cuboidal distribution $(400-800 \mathrm{~nm})$ than the more spherical distributions in RR1000 and the U720Li variants (40$300 \mathrm{~nm}$ ). Tertiary $\gamma^{\prime}$ sizes were assessed in the TEM and found to be comparable for RR1000 and U720Li-LG (6-30nm) whereas U720Li had a somewhat larger size range $(1-45 \mathrm{~nm})$ and N18 had the coarsest tertiary $\gamma^{\prime}$ sizes $(13-63 \mathrm{~nm})$.

Fatigue crack propagation rates are presented graphically in Figure 3 and Figure 4 for all alloys cyclically loaded under the 11-1-1 waveform at both $650^{\circ} \mathrm{C}$ and $725^{\circ} \mathrm{C}$ carried out in air and under vacuum conditions respectively. Corresponding graphs for the 1-20-1-1 waveform at the same temperatures are presented in Figure 5 and Figure 6 in air and vacuum conditions respectively. As expected, both air and vacuum tests show an increasing crack growth rate with increasing $\Delta \mathrm{K}$ and the crack growth rate generally increases at higher temperatures for tests carried out in the same environment. Under 1-1-1-1 cyclic loading for tests carried out in air, the $650^{\circ} \mathrm{C}$ graphs show that U720Li has the fastest crack growth rate, U720Li LG has somewhat better performance, whilst RR1000 has the best performance in terms of crack propagation rate. This relative performance remains the same for the tests carried out at $725^{\circ} \mathrm{C}$, although overall the performance of each material is worse compared with its performance at $650^{\circ} \mathrm{C}$. Under vacuum conditions the crack growth rates of the materials change significantly. According to the available data, at $650^{\circ} \mathrm{C}$ RR 1000 has the highest crack growth rate, with U720Li performing better and U720Li LG achieving the lowest crack growth rate. Although at $725^{\circ} \mathrm{C}$ RR 1000 has the lowest crack growth rate, which increases for U720Li LG and is fastest for U720Li. Under 1-20-1-1 cyclic loading conditions in air at $650^{\circ} \mathrm{C}$ the fatigue crack propagation rates of U720Li and U720Li LG remain similar to those obtained under 1-1-1-1 loading, whereas the fatigue crack propagation rate for RR1000 increases. The material ranking at $650^{\circ} \mathrm{C}$ with a $1-20-1-1$ cycle is that RR1000 and U720Li LG are somewhat similar with U720Li exhibiting the worst fatigue crack propagation performance. With an increase in temperature to $725^{\circ} \mathrm{C}$ under 1-20-1-1 cyclic loading the performance of all the alloys degrades and the ranking of the alloys changes, the best performance being provided by RR1000, then U720Li LG followed by U720Li. Under vacuum conditions and with 1-20-1-1 loading the performance of the alloys generally lies within the upper and lower limits of the fatigue crack propagation rates under 1-1-1-1 conditions

Sample micrographs of the fracture surfaces showing the combined effects of increasing levels of $\Delta \mathrm{K}$ and increasing temperatures under 1-1-1-1 loading cycles for N18 and RR1000 tested in air are presented in Figure 7. Starting with N18 at the lowest temperature and $\Delta \mathrm{K}$ (a) the fracture surface indicates transgranular failure, this appears to be the main type of failure in this case. As the temperature is increased and $\Delta \mathrm{K}$ is increased the type of failure increasingly becomes intergranular, with the most severe conditions (c) leading to mainly intergranular crack propagation, where extensive signs of secondary cracking can also be seen. For RR1000 under the least severe test conditions (b) a mixed but more transgranular mode of crack propagation is observed. As conditions worsen with increasing $\Delta K$ and temperature the mode of crack propagation becomes increasingly intergranular and increasing severity of secondary cracking becomes apparent (d). Although the micrographs for U720Li are not presented here, under similar low $\Delta \mathrm{K}(\approx 20 \mathrm{MPa} \sqrt{\mathrm{m}})$ the crack propagates through this material in an intergranular manner and continues to do so even at increasing levels of $\Delta K$ and temperatures. Again increasing signs of secondary cracking are seen as the severity of the test conditions increases. In U720Li $\mathrm{LG}$ at low $\Delta \mathrm{K}$ the crack propagation mode in the large grain variant of U720 Li is initially quite transgranular. This becomes increasingly intergranular as the temperature increases or $\Delta \mathrm{K}$ is increased again with signs of secondary cracking.

Micrographs of the fracture surfaces showing the combined effects of increasing levels of $\Delta \mathrm{K}$ and increasing temperatures under 1-1-1-1 loading cycles for N18 tested under vacuum conditions are presented in Figure 8. Here the lowest temperature and $\Delta K$ (a) shows a transgranular failure surface, as $\Delta K$ and temperature are increased the failure mode becomes a mixture of intergranular and transgranular crack growth with some secondary cracking seen at the highest temperature and $\Delta \mathrm{K}(\mathrm{b})$, although the proportion of intergranular cracking seen appears to be significantly less than seen with the tests carried out in air. 


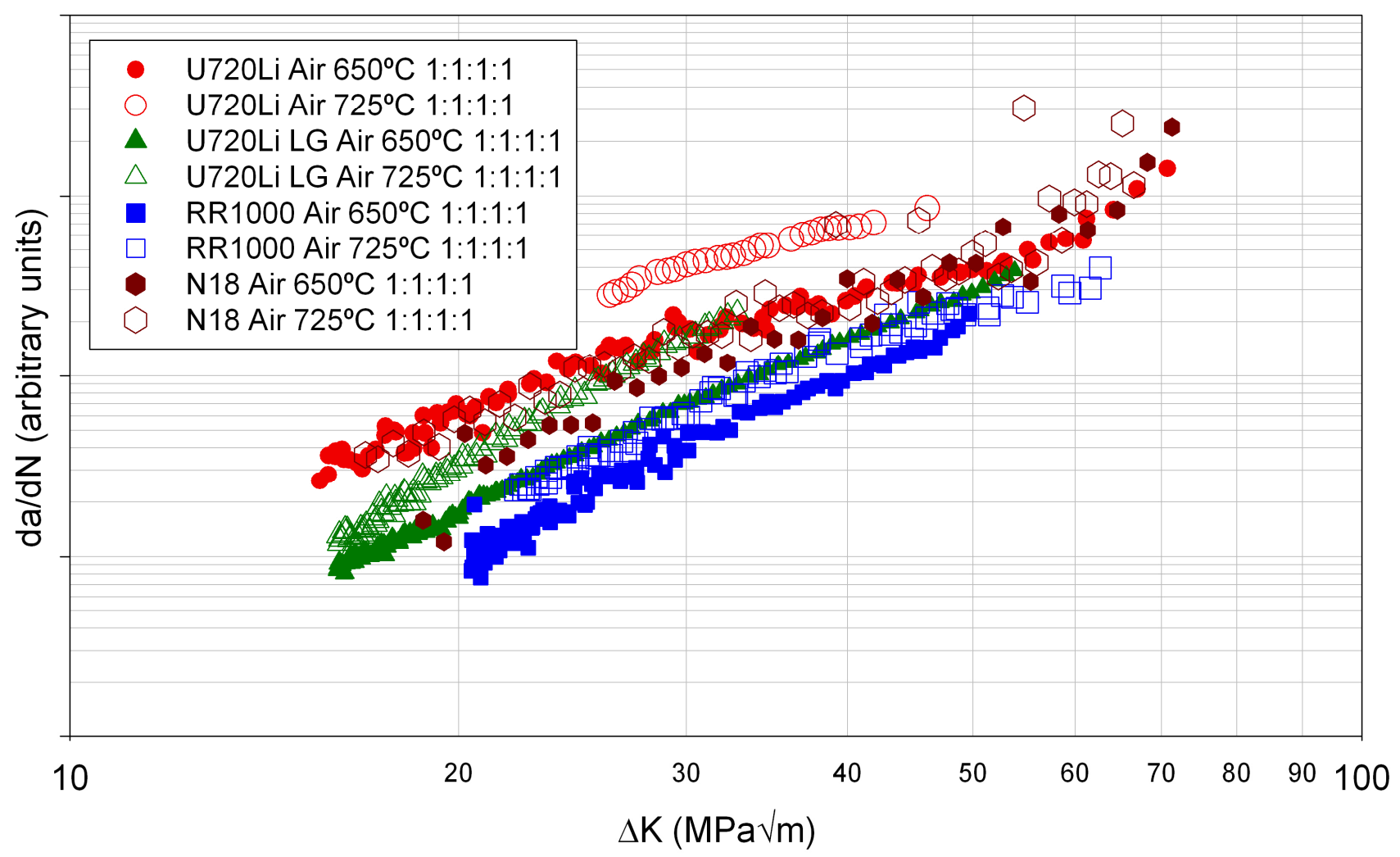

Figure 3 N18, RR1000, U720Li and U720Li LG Fatigue Crack Propagation Rates in Air at $650^{\circ} \mathrm{C}$ and $725^{\circ} \mathrm{C}, 1-1-1-1$

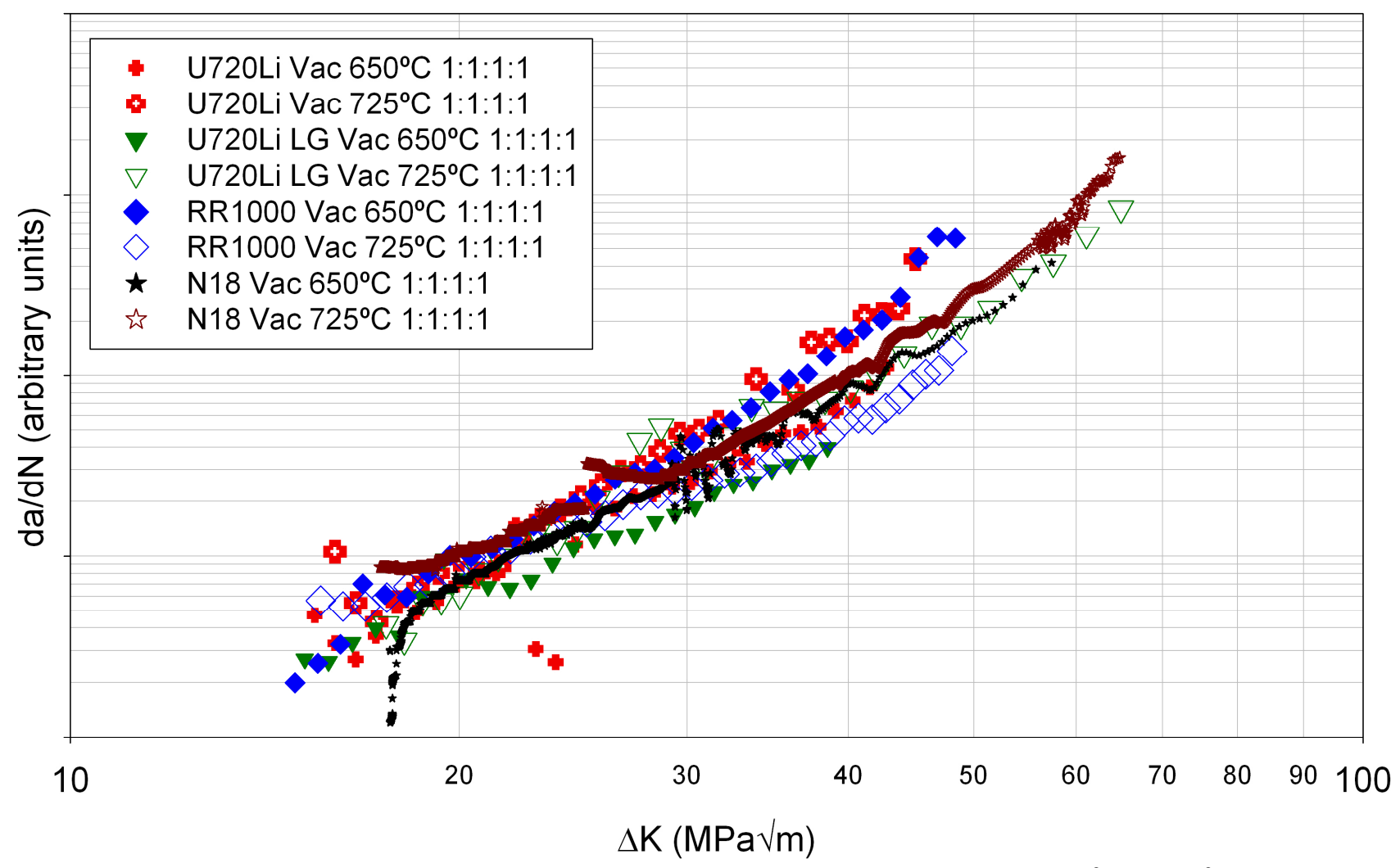

Figure 4 N18, RR1000, U720Li and U720Li LG Fatigue Crack Propagation Rates in Vacuum at $650^{\circ} \mathrm{C}$ and $725^{\circ} \mathrm{C}, 1-1-1-1$ 


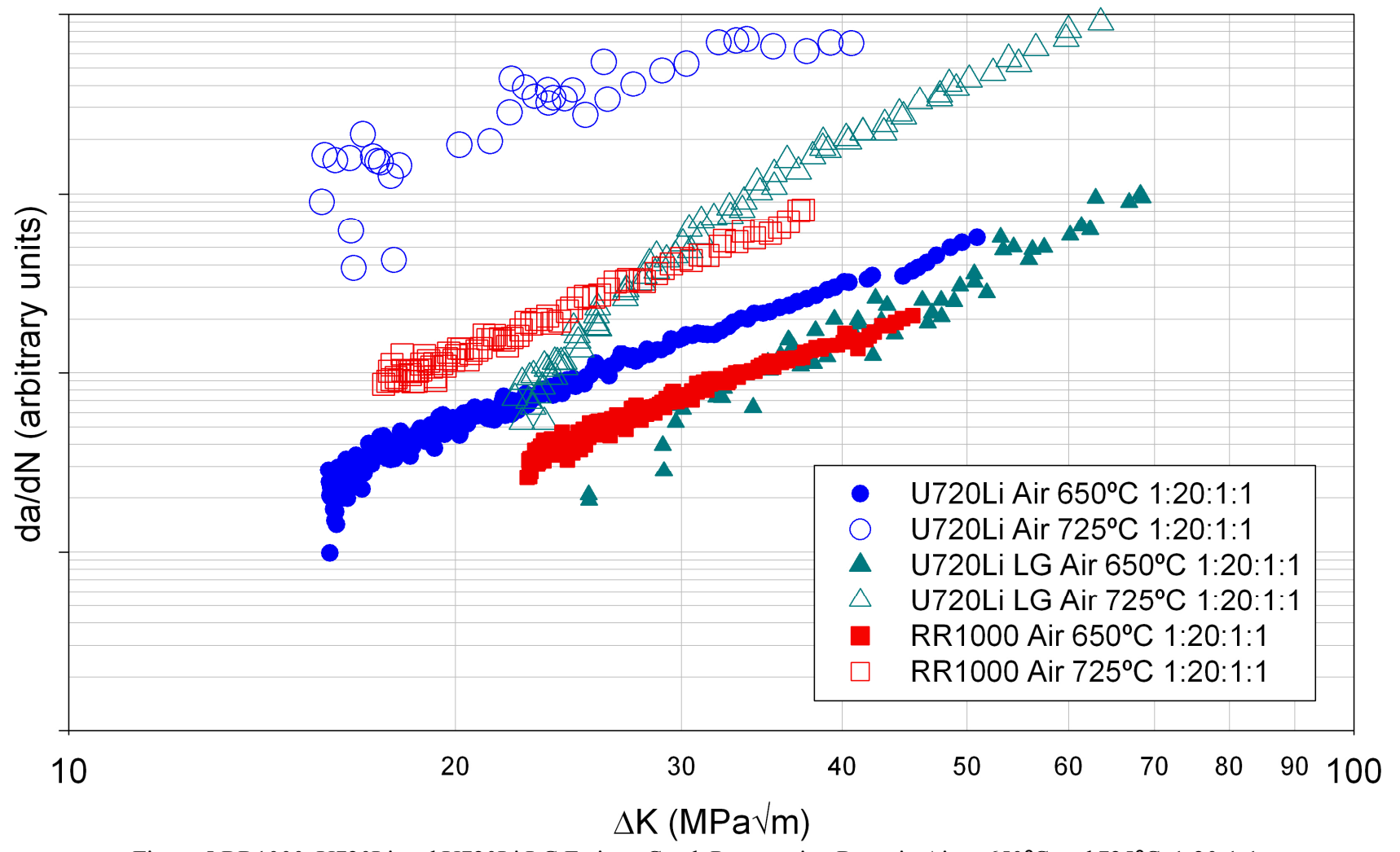

Figure 5 RR1000, U720Li and U720Li LG Fatigue Crack Propagation Rates in Air at $650^{\circ} \mathrm{C}$ and $725^{\circ} \mathrm{C}, 1-20-1-1$

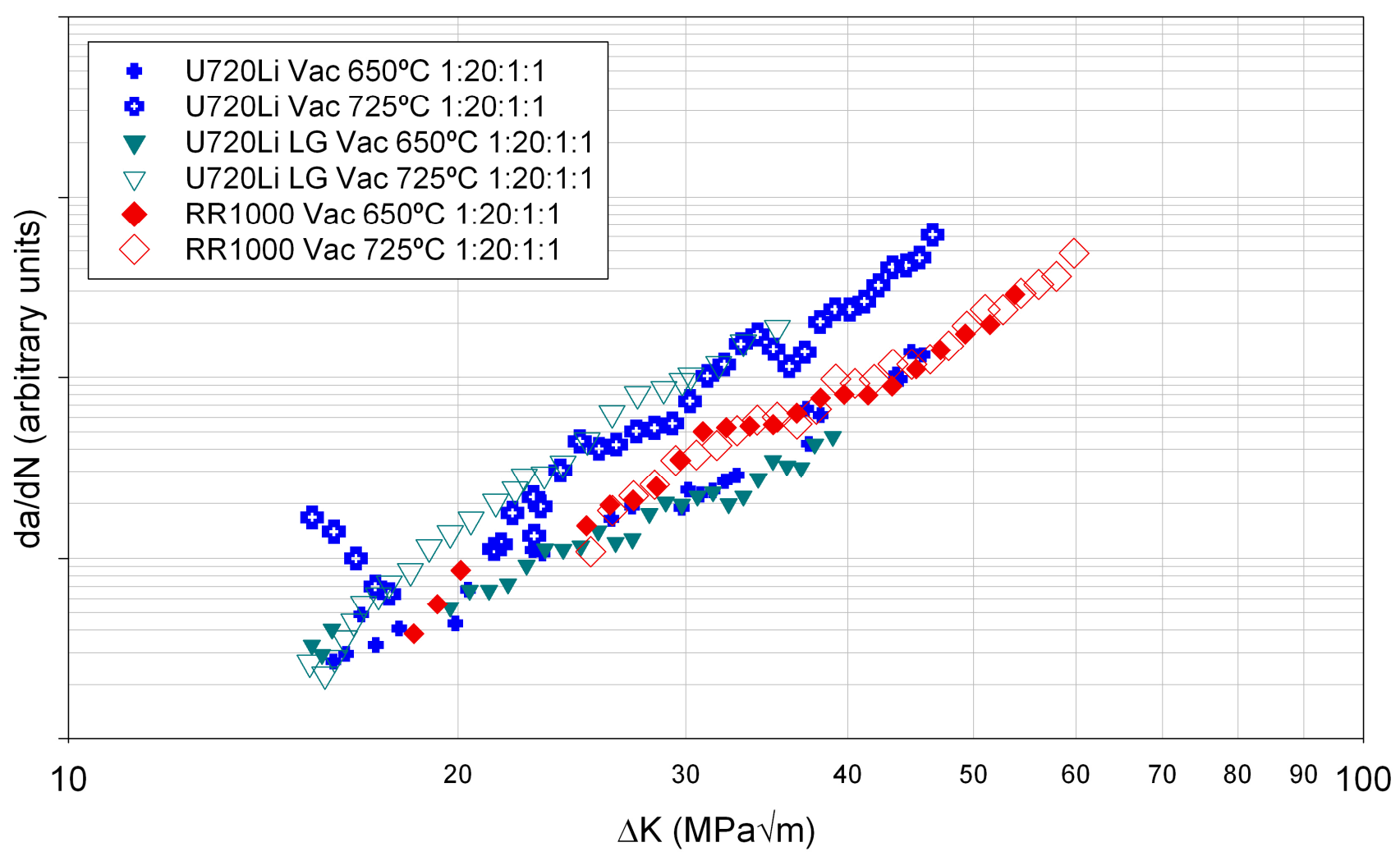

Figure 6 RR1000, U720Li and U720Li LG Fatigue Crack Propagation Rates in Vacuum at $650^{\circ} \mathrm{C}$ and $725^{\circ} \mathrm{C}, 1-20-1-1$ 
(a)

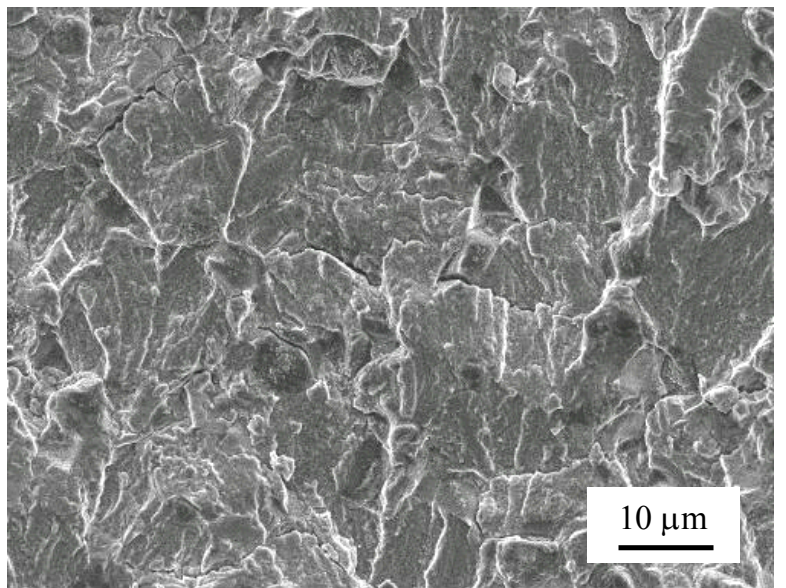

$\mathrm{N} 18650^{\circ} \mathrm{C}$ in air 1-1-1-1 $\Delta \mathrm{K} 21.47 \mathrm{MPa} \sqrt{\mathrm{m}}$

(c)

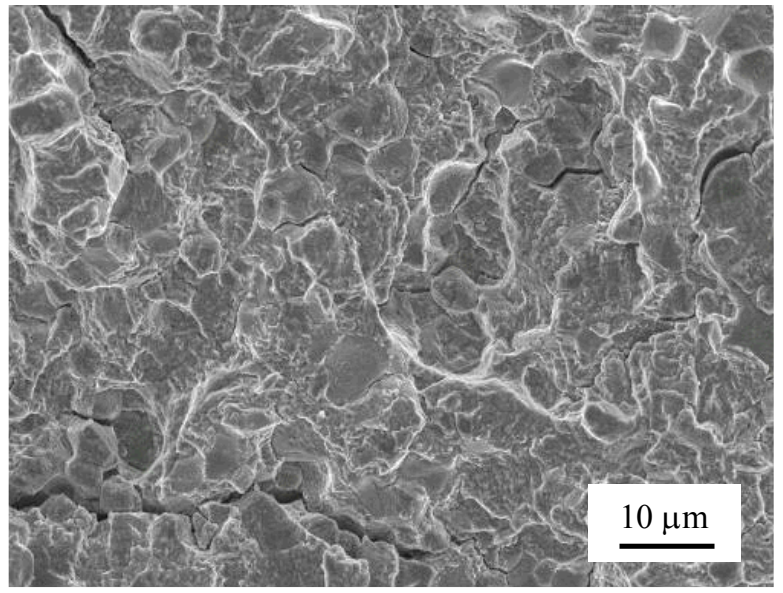

$\mathrm{N} 18725^{\circ} \mathrm{C}$ in air 1-1-1-1 $\Delta \mathrm{K} 41.16 \mathrm{MPa} \sqrt{\mathrm{m}}$

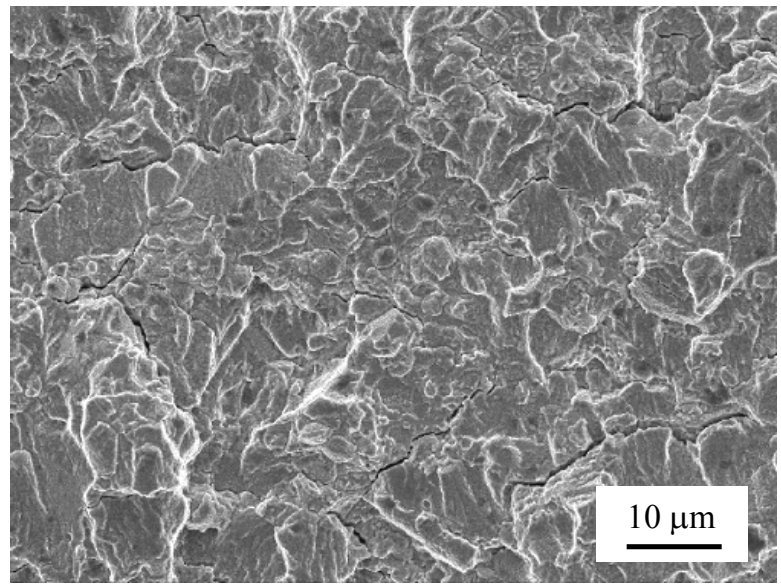

RR1000 $650^{\circ} \mathrm{C}$ in air 1-1-1-1 $\Delta \mathrm{K} 24.4 \mathrm{MPa} \sqrt{\mathrm{m}}$

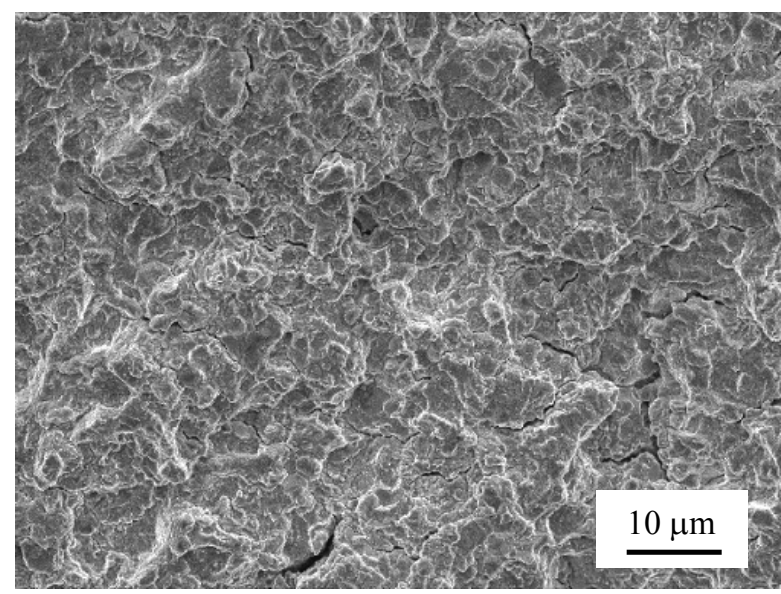

$\mathrm{RR} 1000725^{\circ} \mathrm{C}$ in air 1-1-1-1 $\Delta \mathrm{K} 41.2 \mathrm{MPa} \sqrt{\mathrm{m}}$

Figure 7 N18 and RR1000 fracture surfaces, in air, 1-1-1-1 load cycle, increasing $\Delta K$, increasing temperature, FEG SEM SEI mode

(a)
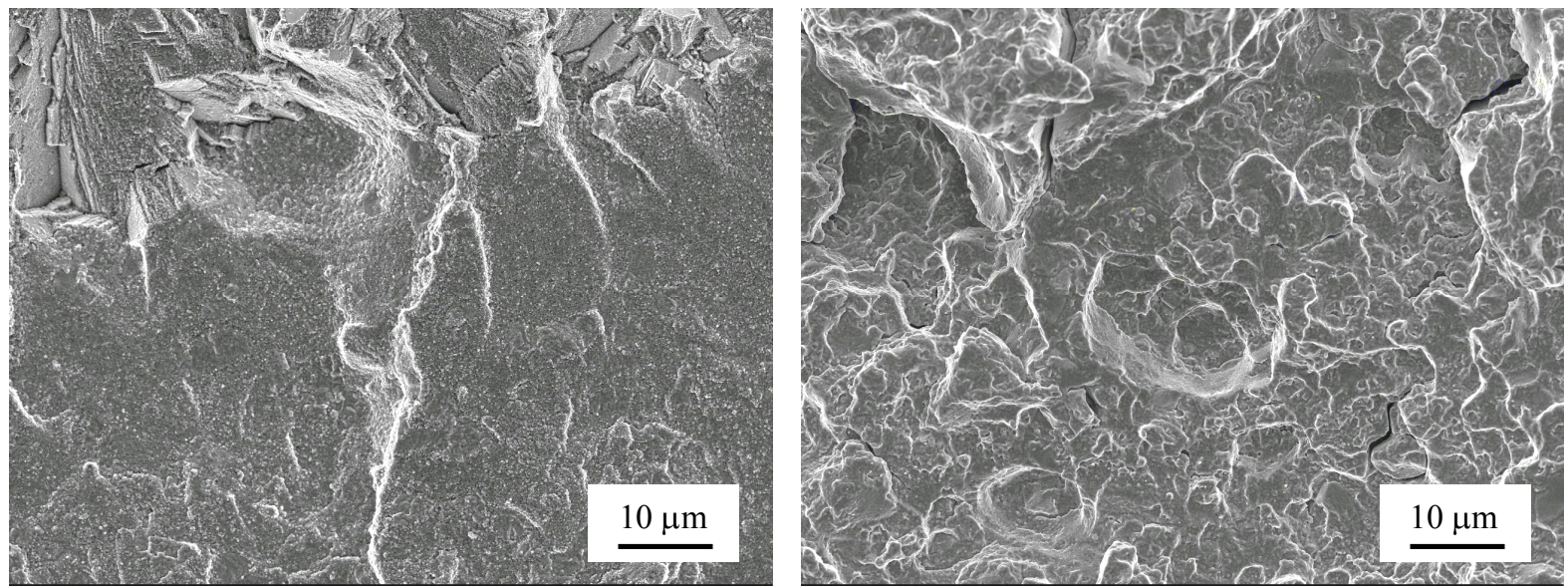

$\mathrm{N} 18650^{\circ} \mathrm{C}$ in vacuum $1-1-1-1 \quad \Delta \mathrm{K} 20 \mathrm{MPa} \sqrt{\mathrm{m}}$

$\mathrm{N} 18725^{\circ} \mathrm{C}$ in vacuum 1-1-1-1 $\Delta \mathrm{K} 40 \mathrm{MPa} \sqrt{\mathrm{m}}$

(d)

(b)

Figure 8 N18 SENB fracture surfaces, in vacuum, 1-1-1-1 load cycle, increasing $\Delta K$, increasing temperature, FEG SEM SEI mode 
(a)

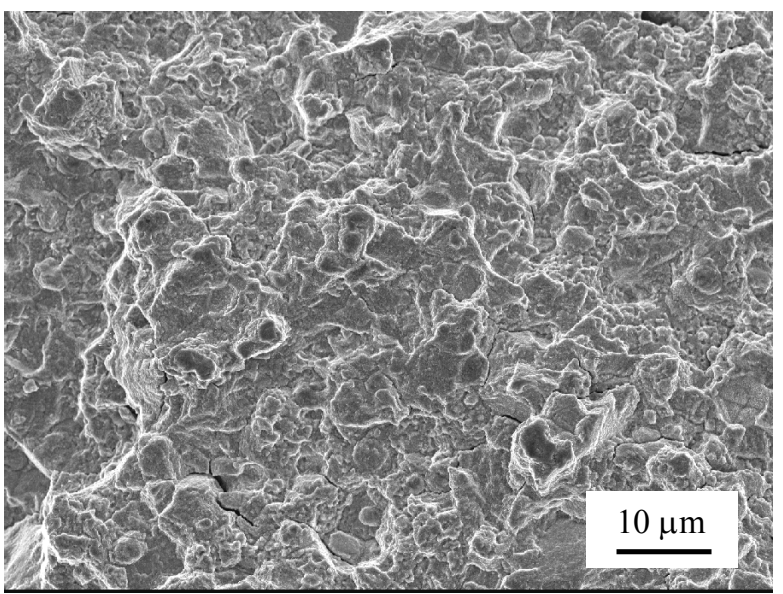

RR1000 $650^{\circ} \mathrm{C}$ in air 1-20-1-1 $\Delta \mathrm{K} 24.8 \mathrm{MPa} \sqrt{\mathrm{m}}$

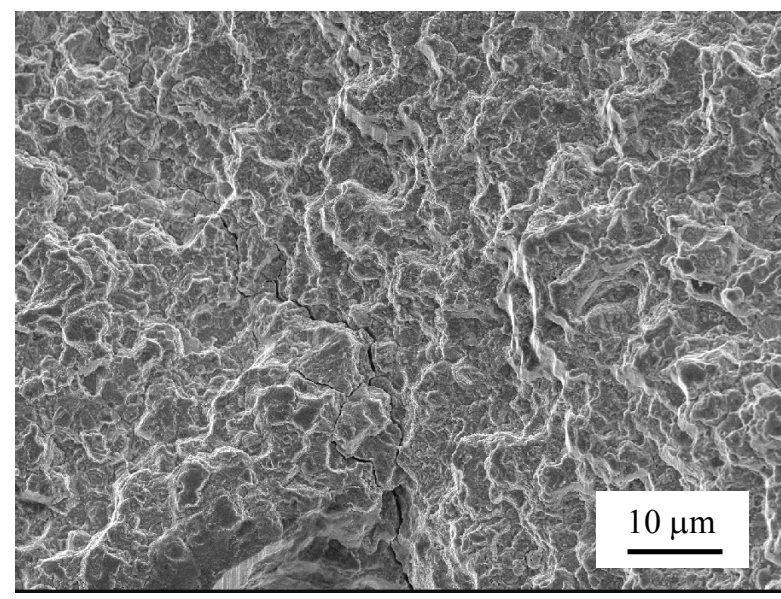

RR1000 $725^{\circ} \mathrm{C}$ in air 1-20-1-1 $\triangle \mathrm{K} 42.5 \mathrm{MPa} \sqrt{\mathrm{m}}$

Figure 9 RR1000 fracture surfaces, in air, 1-20-1-1 load cycle, increasing $\Delta K$, increasing temperature, FEG SEM SEI mode

For RR1000 under vacuum conditions transgranular crack propagation is seen at the lowest temperature and $\Delta \mathrm{K}$, becoming mixed transgranular and intergranular with increasing temperature and $\Delta \mathrm{K}$ and also some signs of secondary cracking. Compared with the air tests the evidence of secondary cracking is significantly reduced. The fracture surfaces for U720Li under vacuum conditions exhibit predominantly intergranular crack growth with an increasing amount of secondary cracking as both temperature and $\Delta \mathrm{K}$ are increased apart from the very lowest $\Delta \mathrm{K}$, which appear to exhibit mixed intergranular and transgranular crack growth. In U720Li LG fracture surfaces under vacuum conditions at low and medium $\Delta \mathrm{K}$ at $650^{\circ} \mathrm{C}$, crack growth appears to be mostly transgranular becoming mixed transgranular and intergranular at the highest $\Delta \mathrm{K}$ for this temperature. At $725^{\circ} \mathrm{C}$ at the lowest $\Delta \mathrm{K}$ crack growth is mixed transgranular and intergranular which becomes predominantly intergranular at higher $\Delta K$. RR1000 fracture surfaces for tests carried out in air under the 1-20-1-1 loading regime are shown in Figure 9. The low $\Delta \mathrm{K}$ at $650^{\circ} \mathrm{C}$ exhibiting intergranular failure (a) increasing in severity as $\Delta \mathrm{K}$ and temperature increases (b).

\section{Discussion}

The grain and $\gamma^{\prime}$ sizes will have a significant influence on the mechanical properties of the alloys such as yield strength, creep and fatigue resistance. All alloys were given (sub-solvus) solution treatments, the $\gamma^{\prime}$ solvus temperatures for N18, U720Li and RR1000 being given in the literature (reproduced in Table II) as about $1190^{\circ} \mathrm{C}[6], 1160^{\circ} \mathrm{C}[2,8]$ and $1160^{\circ} \mathrm{C}[2,7]$ respectively. However, U720Li-LG, RR1000 and N18 have been solution treated relatively close to their $\gamma^{\prime}$ solvus temperature when compared with U720Li, which has resulted in more resolutionising of primary $\gamma^{\prime}$ for U720Li-LG, RR1000 and N18. The reduced amount of primary $\gamma^{\prime}$ at the solution treatment temperature is expected to result in faster grain growth, together with an observed reduction in volume fraction of primary $\gamma^{\prime}$. However the largest grain sizes are observed for U720Li-LG, in the case of RR1000, other grain boundary pinning processes (such as carbides, see below) must be in operation as despite the reduction in primary $\gamma^{\prime}$ the grain size is still quite fine. This may also apply to N18 which has larger outlier grain sizes than RR1000, but also some very fine grains, Figure $2 b$ indicates the possible presence of fine grain boundary particles (which are thought likely to be borides [10]) and these may also explain the retention of a finer grain size $c f$. U720Li LG.

This decrease in the volume fraction of primary $\gamma^{\prime}$ will leave more $\gamma^{\prime}$ forming elements available in solution to form secondary and tertiary $\gamma^{\prime}$ during subsequent ageing processes. As primary $\gamma^{\prime}$ is incoherent with the $\gamma$ matrix an increase in the amount of secondary $\gamma^{\prime}$ (which may be coherent with the matrix) should have a beneficial effect on strengthening the alloy, especially at high temperatures, although grain boundary strengthening may be reduced if grain growth has occurred. Strength values at $650^{\circ} \mathrm{C}$ for the materials in the heat-treated conditions are listed in Table II. It can be seen that the strength ranking is: N18>U720Li>RR1000>U720Li-LG; so N18 has a better strength performance at relatively coarse grain sizes, this may be linked to the higher proportion of $\gamma^{\prime}$ (volume fraction of $\gamma^{\prime}$ in N18 is typically around 55-57\% [11] compared with around 48\% predicted in U720Li [12]) as increased $\gamma^{\prime}$ volume fractions typically impart improved high temperature strength, which becomes a more dominant contribution at higher temperatures.

Creep and oxidation occur principally along grain boundaries due to the preferential diffusion paths they offer, and this weakens the grain boundary and provides a weaker path along which cracking can occur. Such creep and grain boundary oxidation effects will be reduced by a larger grain size (and hence decrease in amount of grain boundary area), but may also be expected to vary with alloy composition and grain boundary character.

The crack propagation modes observed in the N18 fatigue crack propagation tests show that N18 has good resistance to intergranular cracking modes, although some increase in intergranular cracking is seen at higher $\Delta \mathrm{K}$ levels and temperatures. N18 shows far better resistance to fatigue crack propagation at $725^{\circ} \mathrm{C}$ than U720Li. Prior work on U720Li [12] in air and vacuum has indicated that the fast intergranular crack propagation mode observed in $\mathrm{U} 720 \mathrm{Li}$ is principally oxidationfatigue rather than creep-fatigue, as the time dependent effects seen at $725^{\circ} \mathrm{C}$ in vacuum are very small when compared with the time-dependent effects observed in air. The relative amounts of oxidation fatigue and creep fatigue crack propagation can be 
gauged by comparing the relative slopes of fatigue crack propagation rates in air and vacuum (Figure 3 and Figure 4). At a $\Delta \mathrm{K}$ of $20 \mathrm{MPa} \sqrt{\mathrm{m}}$ crack propagation rates in N18 are around four times faster at both $650^{\circ} \mathrm{C}$ and $725^{\circ} \mathrm{C}$ whereas for U720 Li at $725^{\circ} \mathrm{C}$ there is a 10 fold increase in fatigue crack propagation rate between the tests carried out in vacuum and in air. At a higher $\Delta \mathrm{K}$ of $50 \mathrm{MPa} \sqrt{\mathrm{m}}$ the difference between fatigue crack growth rates in air and vacuum for N18 falls to around a factor of two, with fatigue crack propagation rates for both temperatures in air and vacuum conditions converging around $60 \mathrm{MPa} \sqrt{\mathrm{m}}$. This is reflected in the change in slope of the da/dN versus $\Delta \mathrm{K}$ curves between air and vacuum tests, where the higher m-value for the vacuum curves implies an increased contribution from monotonic damage (i.e. creep processes) which are likely to have a greater effect at higher $\Delta \mathrm{K}$ levels, whereas oxidation processes are expected to have an equivalent effect at all $\Delta \mathrm{K}$ levels (lower mvalue). Thus this convergence may reflect the point where pure creep processes in vacuum are starting to have as much effect as combined creep and oxidation processes in air.

It should be noted that an increase in the amount of intergranular failure has been seen in the air tests, with increasing temperatures, which can be linked to oxidation attack along grain boundaries this could overtake any creep processes leading to a fatigue crack growth process dominated by oxidation. Under vacuum conditions creep processes may be expected to play more of a role as oxidation is suppressed and to be the cause of any intergranular failure mechanisms observed. Crack propagation studies in N18 [13] have indicated increased intergranular crack growth modes with long hold times, with mostly transgranular crack growth modes observed at $650^{\circ} \mathrm{C}$ with lower hold times [14], in agreement with this work. The hold time effect in N18 has been linked to intergranular oxidation assisted embrittlement and creep strains due to stress relaxation during the hold time (where the stress relaxation has been found to be largely dependent on $\gamma^{\prime}$ size). Vacuum tests carried out by Andrieu and Pineau and Weber et al on N18 [13,15] showed significantly less effect of hold time at $650^{\circ} \mathrm{C}$ and the failure mode maintained a transgranular character.

In considering the relative fractographic information from the failed samples, for tests carried out in air, at low $\Delta \mathrm{K}(\sim 20$ $\mathrm{MPa} \sqrt{\mathrm{m}}) \mathrm{N} 18$ at $650^{\circ} \mathrm{C}$ exhibits the most transgranular failure on the fracture surface, followed by U720Li-LG. RR1000 exhibits mixed intergranular and transgranular failure modes under these conditions whilst U720Li shows mostly intergranular failure. At the increased temperature of $725^{\circ} \mathrm{C}$ and increased $\Delta \mathrm{K}$, the mode of failure becomes increasingly intergranular for N18, U720Li LG and RR1000, further indication that the grain boundary oxidation and creep processes discussed earlier predominate. Especially when this it contrasted with the fractography from the tests carried out under vacuum conditions, where transgranular crack growth is evident to higher values of temperature and $\Delta K$ when compared to the equivalent tests carried out in air.

Comparison with previous tests conducted in vacuum has indicated that at these temperatures oxidation-fatigue processes swamp pure creep-fatigue processes [3]. This is also reflected in the new tests in N18, compared with existing data as described above. Further evidence of this can be seen in the fatigue crack propagation rates at $650^{\circ} \mathrm{C}$, Figure 3, where the large grain variety of U720Li-LG has improved fatigue crack propagation performance in air over the as-received U720Li, yet performance under vacuum conditions, Figure 4, shows a much smaller difference in the performance of the two variants. The better crack propagation performance shown in U720Li-LG when compared with U720Li can therefore be understood in terms of reduced grain boundary area, where grain size effects alone have been varied. RR1000 achieves the lowest crack propagation rate in air over all $\Delta \mathrm{K}$ levels and yet has a grain size intermediate between U720Li and U720Li-LG. This shows that grain size alone cannot account for the crack propagation rates across the alloys. The influence of additional factors such as alloy chemistry and coherent $\gamma^{\prime}$ distributions, which will strongly influence the alloys' flow strengths at elevated temperature, and slip behaviour may play a role in transport of oxygen to the grain boundaries [16]. Previous short crack studies in some of these alloys at $650^{\circ} \mathrm{C}$ [17] have indicated that changes in the finer $\gamma^{\prime}$ distributions and the concomitant effects on slip behaviour only have a minor effect when compared with grain size effects. Alloy chemistry will also play an important part in the control of oxidation rates along grain boundaries in RR1000, N18 and the U720Li variants.

Amongst the differences in alloy chemistry, one important aspect here is the addition of $\mathrm{Hf}$ to the RR1000 and N18 alloys and Ta to RR1000. For fatigue resistance it is important that these elements will modify the MC carbides to become enriched in Hf and Ta and under certain conditions $\mathrm{MC}$ carbide with a wide range of compositions from $\mathrm{Hf}$ lean (Ti,Ta)C to Hf rich MC can form [18]. The decomposition of the MC carbides during heat treatment and exposure at high temperatures will cause the formation of lower carbides such as the $\mathrm{Cr}$-rich $\mathrm{M}_{23} \mathrm{C}_{6}$ carbides which form predominantly at grain boundaries in a range of superalloys[19], including RR1000 [20]. As C diffusion is orders of magnitude faster than diffusion of metallic alloying elements, and $\mathrm{Ta}$ and $\mathrm{Hf}$ diffusion is particularly slow, the rate of $\mathrm{M}_{23} \mathrm{C}_{6}$ formation is dependent mostly on the decomposition rate of the Ta and $\mathrm{Hf}$ containing MC carbides. Thus, in combination with heat treatment schedule, Ta and $\mathrm{Hf}$ additions offer the possibility of fine tuning the $\mathrm{M}_{23} \mathrm{C}_{6}$ distribution on grain boundaries and the microchemistry of the grain boundaries. In addition, the $\mathrm{MC}$ carbides will to some extent be located preferentially at grain boundaries, because they slow down grain growth. These carbides at grain boundaries are expected to influence fatigue crack propagation along grain boundaries through two mechanisms. Firstly, formation of substantial amounts of the Cr-rich $\mathrm{M}_{23} \mathrm{C}_{6}$ carbides at grain boundaries will cause local $\mathrm{Cr}$ depletion of the matrix at the grain boundaries and hence change local susceptibility to corrosion and the corrosion products formed, which will degrade FCG resistance in air. This effect is also influenced by the increased Mo content of RR1000, which will substitute for some of the $\mathrm{Cr}$ in the formation of $(\mathrm{Cr}, \mathrm{Mo})_{23} \mathrm{C}_{6}$. On the other hand, the presence of carbides at grain boundaries will reduce creep by grain boundary sliding, and this effect is especially important for finer grained alloys. Thus carbides at grain boundaries will improve FCG resistance in vacuum and can improve FCG resistance in air provided the detrimental effect of $\mathrm{Cr}$ depletion is kept limited. The beneficial effect will become more important if a dwell at high load is included. It has been stated that the composition and heat treatment of RR1000 is optimised to provide the optimum grain boundary carbide distribution with optimum size of carbide grain boundary particles of 350 to $550 \mathrm{~nm}$ [20]. On the basis of the present discussion it is suggested that the superior FCG resistance of RR1000 is related to a (near) optimised combination of heat treatment and Ta and $\mathrm{Hf}$ additions which produces a beneficial distribution of fine carbides 
at grain boundaries and an beneficial local chemistry at the grain boundaries. This optimisation ultimately proves more beneficial compared to the increased grain size of the U720Li-LG variant, which is thought to have grain boundary particle distributions and chemistry that are not optimised for FCG resistance.

\section{Apparent activation energy analysis}

Since the failure processes assessed in the previous discussion are essentially multi-mechanistic, clearly defining the dominant or rate-determining process is complex and open to many alternative interpretations. An alternative method of gaining information on the mechanisms involved in these tests is to assess the apparent activation energy of the fatigue crack process, as proposed recently by Starink and Reed [4]. This method assumes that progress of many of the processes discussed so far is dominated by a thermally activated reaction and as such the rate is proportional to an Arrhenius term. Examples of such processes are, thermally activated dislocation motion (including creep), solid state reactions, gas-solid reactions (including oxidation), and diffusion, as applied to fatigue crack propagation. When adopted for fatigue crack propagation, the following relation is derived [4]:

$$
\frac{d a}{d t} \propto k_{F C G} f(a) \exp \frac{-Q}{R_{g} T}
$$

Where $\mathrm{d} a / \mathrm{d} t$ is the rate of crack growth, $k_{\mathrm{FCG}}$ is a term that contains all non temperature dependent terms, except for the length of the crack, $f$ is a function depending only on the extent of the reaction completed, $Q$ is the activation energy, $R_{\mathrm{g}}$ is the gas constant $(8.31 \mathrm{~J} / \mathrm{mol} . \mathrm{K})$ and $T$ is the temperature. With the product of $k_{\mathrm{FCG}}$ and $f(\mathrm{a})$ being kept constant by defining a crack driving force appropriate for the material's loading condition, such as $\Delta \mathrm{K}$ in this case. Thus, as the product $k_{\mathrm{FCG}}$ and $f(\mathrm{a})$ is kept constant, then the (apparent) activation energy, $E_{\text {app }}$ can be obtained from two fatigue crack propagation tests at two temperatures, $T_{2}$ and $T_{1}$ by using [4]:

$$
E_{a p p}=\frac{-R_{g}}{T_{2}^{-1}-T_{1}^{-1}} \ln \left(\frac{d a}{d N}\left(T_{2}\right) / \frac{d a}{d N}\left(T_{1}\right)\right)
$$

Which assumes that the loading cycles at the two temperatures are identical and as such $\mathrm{d} a / \mathrm{d} t$ is proportional to $\mathrm{d} a / \mathrm{d} N$.

Using this method and by relating this apparent activation energy to the activation energies required for various mechanisms to occur it should be possible to identify which thermally activated mechanisms are active. Three main groups of thermally activated mechanisms can be attributed to time-dependent crack growth behaviour at temperature: (1) localized oxidation at the crack tip and/or dynamic embrittlement (2) creep (especially at grain boundaries) (3) thermally activated modes of dislocation movement, which may influence, amongst others, the monotonic mechanical properties of the material, most notably the yield strength. The relative importance of these processes can change with temperature and crack tip stress cycle, affecting the apparent activation energy as it is assessed between different temperatures (unlike other thermally activated reactions where the activation energy generally undergoes very little change with temperature). Detailed derivations/discussions of the different expected apparent activation energies for the different underlying mechanisms, as well as experimental and mechanistic issues related to linearity of the $E_{\text {app }}$ versus $1 / T$ curves, can be found in [4]

Table III Activation energies for processes contributing to high temperature FCG. GB stands for grain boundary after [4].

Process contributing to high temperature Activation
\begin{tabular}{|l|l} 
fatigue crack growth & energy \\
\hline
\end{tabular}

\begin{tabular}{|l|l|}
\hline \multicolumn{2}{|c|}{ Single process } \\
\hline Oxidation of carbides & $\sim 250 \mathrm{~kJ} / \mathrm{mol}$ \\
\hline Dynamic embrittlement & $\sim 250 \mathrm{~kJ} / \mathrm{mol}$ \\
\hline Grain boundary creep & $\sim 150 \mathrm{~kJ} / \mathrm{mol}$ \\
\hline Change in static properties & $\sim 0-60 \mathrm{~kJ} / \mathrm{mol}$ \\
\hline \multicolumn{2}{|c|}{ Mixed processes } \\
\hline $\begin{array}{l}\text { Dynamic embrittlement of GBs and creep of } \\
\text { ligaments }\end{array}$ & $\sim 250 \mathrm{~kJ} / \mathrm{mol}$ \\
\hline GB creep failure + oxidation dominated FCG & $\sim 150-250 \mathrm{~kJ} / \mathrm{mol}$ \\
\hline $\begin{array}{l}\text { GB creep failure }+ \text { non thermally activated } \\
\text { failure }\end{array}$ & $\sim 0-150 \mathrm{~kJ} / \mathrm{mol}$ \\
\hline
\end{tabular}

Activation energies for all four materials tested in air and vacuum under 1-1-1-1 and 1-20-1-1 load cycles for $\Delta \mathrm{K}=30 \mathrm{MPa} \sqrt{\mathrm{m}}$ are shown in Figure 10.

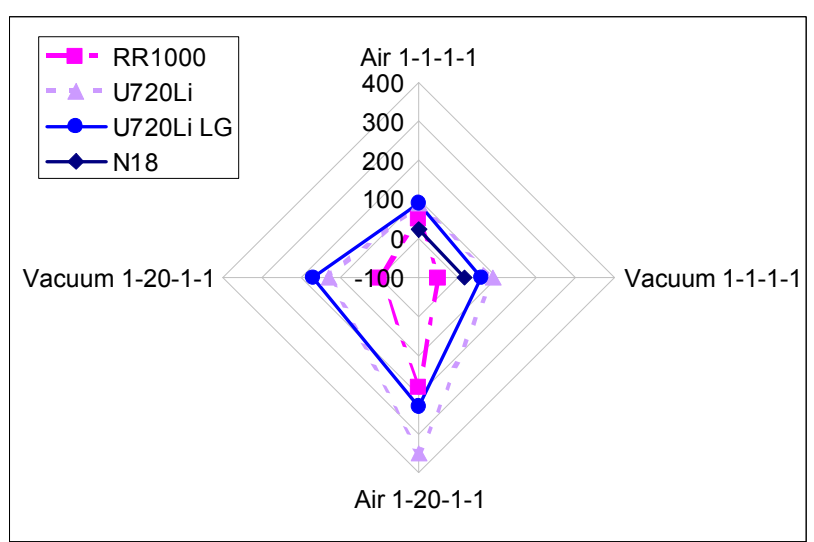

Figure 10 Radar plot of apparent activation energies $(\mathrm{kJ} / \mathrm{mol})$ for fatigue crack propagation of N18, RR1000, U720Li and U720Li LG under air and vacuum conditions with 1-1-1-1 and 1-20-1-1 load cycles for $\Delta \mathrm{K}=30 \mathrm{MPa} \sqrt{\mathrm{m}}_{\text {. }}$.

The activation energies measured for the 1-20-1-1 tests in the U720 Li variants are between 250 to $350 \mathrm{~kJ} / \mathrm{mol}$, which taken in conjunction with the fractography results and consideration of crack growth rate trends can be related to FCG dominated by oxidation. However, the apparent activation energies of U720Li LG and U720Li for 1-1-1-1 cycles are substantially lower (80$100 \mathrm{~kJ} / \mathrm{mol}$ ), indicating that oxidation provides a much more limited contribution to the failure processes for this cycle. The activation energies for FCG in air for RR1000 and N18 are much lower than any known diffusion process (at grain boundaries or in the bulk) and apparent activation energies for FCG in the U720Li variants. The activation energies for RR1000 and N18 also show a clear decreasing trend with increasing $\Delta K$, and activation energies become nearly zero for $\Delta K=50 \mathrm{MPa} \vee \mathrm{m}$. It is thought that these observations indicate that oxidation or creep is not the rate determining step in FCG for medium to high $\Delta K$. (This is not to say the oxidation does not occur, it means that the oxidation that occurs is not significantly enhancing FCG.) In this case, where higher crack growth rates occur, pure cyclic (or mechanical) 
fatigue processes may be considered to predominate. Consistent with the above analysis, the apparent activation energy for FCG is reduced to zero for testing in vacuum of RR1000. The graphical presentation of activation energies through the radar plot (Figure 10) allows some direct observations about the relative importance of mechanisms. In a single figure this shows directly that in terms of FCG degradation with temperature between 650 and $725{ }^{\circ} \mathrm{C}$ RR1000 is superior under all four testing conditions, with N18 showing the next best performance (for the test conditions studied to date). The activation energies suggest that oxidation is not the rate determining process for FCG in RR1000, but for U720Li (the smaller grain variant studied here) oxidation related FCG is dominant for tests in air with a dwell. The figure also suggests that there is no significant change in the main mechanism for FCG for the two U720Li variants when atmosphere is changed from air to vacuum in the absence of a dwell (during the 1-1-1-1 test cycle). It should be noted that the apparent activation energy reflects the degree of thermal activation of a process, and is not a reflection of how much it may affect crack propagation resistance in an individual alloy. Hence the activation energy for crack propagation in air for U720Li-LG is similar to that of U720Li, which is consistent with oxidation-fatigue at grain boundaries being dominant for both materials, with the difference in FCG rate being determined predominantly by the reduced grain boundary area. In the case of RR1000 and N18 however, the improvement in grain boundary character discussed earlier in the paper (through manipulation of either carbides or borides on the grain boundaries) may be contributing to improved resistance to creep processes, but also oxidation processes, assuming any $\mathrm{Cr}$ depletion in forming the grain boundary particles is limited. This may be reflected in the low apparent activation energies for these alloys.

\section{Summary and Conclusions}

The fatigue crack propagation resistance of 4 turbine disc alloys has been compared at $650^{\circ} \mathrm{C}$ and $725^{\circ} \mathrm{C}$ in air and vacuum, under a 1-1-1-1 and a 1-20-1-1 trapezoidal loading waveform. Increasingly intergranular crack growth modes (including secondary cracking) are seen for all 4 alloys with: increased temperature, higher $\Delta \mathrm{K}$ levels, air $c f$. vacuum test conditions. Comparisons of fractography changes, FCG changes with test condition and an apparent activation energy analysis have allowed the multi-mechanistic nature of these failure processes to be drawn out more clearly. Oxidation fatigue seems to be the dominant time-dependent process contributing to the intergranular failure process, although some element of intergranular failure was seen at the highest temperatures and $\Delta \mathrm{K}$ levels in vacuum, indicating that pure creep fatigue processes can play a role when oxidation is eliminated. The best resistance against oxidation fatigue appears to be shown by RR1000, with a larger grain size conferring a benefit for crack growth behaviour in time-dependent fatigue (in the absence of other factors). The grain boundary character of RR1000 and N18 is deduced to play an important role in their improved high temperature fatigue crack growth resistance over the U720Li variants.

\section{Acknowledgements}

Thanks are due to QinetiQ Ltd. and EPSRC for financial support and to SNECMA Moteurs, QinetiQ and Rolls-Royce for materials supply. Technical discussions with Dr J. Brooks (QinetiQ, UK), and technical contributions by Drs H.T. Pang and M. Henderson are gratefully acknowledged.

\section{References}

[1] S. Everitt, M.J. Starink, H.T. Pang, I.M. Wilcock, M.B. Henderson and P.A.S. Reed, Materials Science and Technology, 2007, 23 (12) 1419-1423.

[2] S.J. Hessell, W. Voice, A., W. James, S.A. Blackham, C.J. Small and M.R. Winstone, US Patent 5897718, 1999.

[3] H.T. Pang and P.A.S. Reed, Mater. Sci. Eng. A, 2007, 448, 67-79.

[4] M.J. Starink and P.A.S. Reed, Mater. Sci. Eng. A, in press Feb 2008, doi:10.1016/j.msea.2008.02.016.

[5] A.Wisbey, I.Di Martino, J.W.Brooks, S. Everitt and P.A.S. Reed, Proc. of Parsons 2007, 7th Int. Charles Parsons Turbine Conference: Power Generation in an Era of Climate Change, 1113 Sept. 2007, University of Strathclyde, Glasgow, UK, 309-319.

[6] Y. Honnorat, Mater. Tech., 1991, 79, 19-29.

[7] H.T. Pang and P.A.S. Reed, to be published.

[8] J. Mao, K.M. Chang, W. Yang, K. Ray, S.P. Vaze and D.U. Furrer, Metall. Mater. Trans. A, 32, 2441-2452.

[9] H.T. Pang, (2003) 'Effect of microstructure variation on turbine disc fatigue lives', $\mathrm{PhD}$ Thesis, University of Southampton, UK.

[10] E. Cadel, D. LeMarchand, S. Chambreland, D. Blavette, Acta Materialia, 2002, 50, 957-966.

[11] C. Raisson and J.H. Davidson, High Temperature Materials for Power Engineering, E. Bachelet et al., Ed., Liege-Kluwer Academy, 1990, 1405.

[12] Hide N.J., Henderson M.B. Reed P.A.S. Ninth Int.l Symp. on Superalloys, Seven Springs, PA, USA, 17-21 Sept. 2000, Minerals, Metals and Materials Society/AIME, Superalloys 2000, .495-503.

[13] Andrieu, E and Pineau, A. Journal de Physique IV, 1999, 9 (9). Pr9-3 - Pr9-11

[14] Sansoz, F., Brethes, B. and Pineau, A. Fatigue Fract. Eng. Mater. Struct., 2002, 25, 41-53.

[15] M. Weber, M. Rodig, F. Schubert, E.E. Affeld, and M. Kraus Materials for Advanced Power Engineering, Part II, ed. D. Coutsouradis et al, 1994, 961-969.

[16] Zheng D., Rosenberger A., Ghonem H. Materials Science and Engineering, 1993, A161, 13-21.

[17] Pang, H.T. and Reed, P.A.S. Int. J. Fat. 2003, 25 1089-1099.

[18] M.J. Starink, H. Cama and R.C. Thomson, Scr. Mater., 1997, 38, 73-80.

[19] R.C. Thomson and M.J. Starink, US Patent 6219404, 2001.

[20] A.J. Manning, D. Knowles, C.J. Small, US Patent Application "Nickel base superalloy" 20020041821, 2002. 